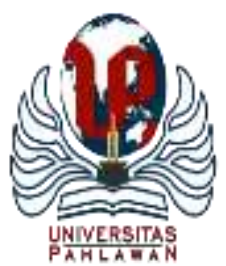

\title{
JURNALBASICEDU
}

Volume 5 Nomor 6 Tahun 2021 Halaman 5227 - 5233

Research \&Learningin Elementary Education

https://jbasic.org/index.php/basicedu

\section{Revitalisasi Pancasila dalam Memfilter Dampak Globalisasi dan Era Revolusi Industri 4.0}

\section{Alexandria Sarah Vania ${ }^{1 凶}$, Dinie Anggraeni Dewi ${ }^{2}$, Fajriatur Robi’ah ${ }^{3}$, Ikhsan Fitrian Catur Nugraha $^{4}$, Yayang Furi Furnamasari ${ }^{5}$}

Program Studi Pendidikan Guru Sekolah Dasar Universitas Pendidikan Indonesia, Indonesia 1,2,3,4,5 E-mail: alexandriasv@upi.edu ${ }^{1}$, dinieanggraenidewi@upi.edu ${ }^{2},{\text { fajriya21@ } \text { upi.edu }^{3}}, \underline{\text { ikhsanfcn2001 @ upi.edu }}^{4}$, furi2810@upi.edu ${ }^{5}$

\begin{abstract}
Abstrak
Globalisasi dan Pancasila sangatlah berkesinambungan dikarenakan adanya perkembangan zaman yang membuat pancasila harus memiliki berbagai inovasi bagi penerapannya. Pada kesempatan penelitian kali ini bertujuan untuk mengetahui beberapa pengaruh globalisasi dan Revolusi Industri 4.0 yang mungkin berdampak buruk terhadap nasionalisme suatu negara di era modern ini dimana sebagian besar rasa nasionalisme negara tersebut berkurang bahkan tersesat. Penulis dalam penelitian menggunakan metode kualitatif dengan studi literatur meneliti dengan menelaah beberapa sumber materi dari jurnal terakreditas sinta juga jurnal bereputasi, maupun bukulalu teori pembahasannya dianalisis dan ditelaah yang hasil akhirnya dijadikan suatu simpulan. Hasil dari penelitian ini adalah bahwa dalam era Revolusi Industri 4.0 dan keberadaan globalisasi dapat memperluas wawasan atau pemikiran sosial dalam skala global dan berdampak positif maupun negatif bagi masyarakat Indonesia. Oleh karena itu, peran dari pancasila itu sendiri sebagai landasan ideologi bangsa Indonesia sangatlah diperlukan. Kesimpulannya ialah peran Pancasila dan revitalisasi dalam upaya menyaring dampak negatif globalisasi harus diwujudkan oleh bangsa Indonesia melalui penerapan nilai baik pancasila di, guna menjaga keutuhan bangsa dan bangsa Indonesia.
\end{abstract}

Kata Kunci: Pancasila, Globalisasi, Era revolusi industri 4.0

\begin{abstract}
Globalization and Pancasila are very sustainable because of the times that make Pancasila must have various innovations for its implementation. On this occasion, this research aims to find out some of the effects of globalization and the Industrial Revolution 4.0 which may have a negative impact on the nationalism of a country in this modern era where most of the country's sense of nationalism is reduced and even lost. The author in this study uses a qualitative method with a literature study by examining several sources of material from Sinta accredited journals as well as reputable journals, as well as books, then the theory of discussion is analyzed and studied, the final results are used as a conclusion. The results of this study are that in the era of the Industrial Revolution 4.0 and the existence of globalization, it can broaden social insight or thinking on a global scale and have positive and negative impacts on the people of Indonesia. Therefore, the role of Pancasila itself as the ideological foundation of the Indonesian nation is very necessary. The conclusion is that the role of Pancasila and revitalization in an effort to filter the negative impacts of globalization must be realized by the Indonesian people through the application of the good values of Pancasila in order to maintain the integrity of the Indonesian nation and nation.
\end{abstract}

Keywords: Pancasila, Globalization, Industrial revolution era 4.0

Copyright (c) 2021 Alexandria Sarah Vania, Dinie Anggraeni Dewi, Fajriatur Robi'ah, IkhsanFitrianCatur Nugraha, Yayang Furi Furnamasari

$\triangle$ Corresponding author :

Email : alexandriasv@upi.edu

DOI : https://doi.org/10.31004/basicedu.v5i6.1612

ISSN 2580-3735 (Media Cetak)

ISSN 2580-1147 (Media Online) 
5228 Revitalisasi Pancasila dalam Memfilter Dampak Globalisasi dan Era Revolusi Industri 4.0 Alexandria Sarah Vania, Dinie Anggraeni Dewi, Fajriatur Robi’ah, IkhsanFitrianCatur Nugraha, Yayang Furi Furnamasari

DOI: https://doi.org/10.31004/basicedu.v5i6.1612

\section{PENDAHULUAN}

Menurut (Herlambang Y. t., 2015) pendidikan dapat menimbulkan dan juga memperkokoh peradaban yang bermartabat. Dilansir menurut (Kaelan, 2010), Pendidikan Pancasila mempunyai artidanperan bagi Indonesia yakni guna mendidik juga sebagai jati diri yaitu ideologi bangsa juga filsafat serta menjadi alat pemersatu bangsa. Pancasila juga sangat memiliki peran sebagai transeter masyarakat atau pandangan hidup bangsa maupun masyarakat Indonesia yang dijunjung olehsetiap warga negara sebagai dasar negara. Pancasila juga berperan sebagai pemersatu bangsa yang bersifat majemuk. Dengan peran dan kedudukan Pancasila yang sangat penting tersebut dapat kita ketahui bahwa Pancasila akan berpengaruh tinggi besar bagi masyarakat juga bangsa Indonesia dan membawa perubahan-perubahan bagi masa depan bangsa. Kondisi demikian dapat terjadi karena bangsa Indonesia memiliki perjalanan sejarah yang sangat kompleksitas. Dengan keberagaman yang dimiliki Indonesia contohnya yakni seperti keberagaman budaya, kepercayaan, bahasa, ribuan pulau, suku bangsa, adat dan masih banyak lainnya haruslah mutlak menjadi alat pemersatu kita.

Dilansir lebih lanjut menurut (Bakri, 2016) adanya perkembangan di era modern ini yakni revolusi industri 4.0 masyarakat dari berbagai penjuru dunia sudah menggunakan internet of thinking guna dimanfaatkan sebagai pergerakan keaktifan kegiatan manusia dalam kehidupan sehari-hari. Sejak menduduki abad 21 Indonesia banyak sekali ditemukan berbagai tahapan perubahan yang muncul. Maka dari itu masyarakat Indonesia dapat dengan mudah mengenali budaya asing dan bahkan menjadikannya sebagai trand setter.

(Efendi, 2020) Pancasila di negara kita dijadikan sebagai pandangan hidup bangsa yang berfungsi sebagai alat pemegang atau senter dan acuan bagi masyarakat di Indonesia. Pada era yang modern ini atau globalisasi era revolusi industri 4.0, banyak masyarakat Indonesia yang belum dan bahkan tidak mengetahui makna dari ideologi kita yakni Pancasila, padahal jika ditinjau sejarah dalam perumusan Pancasila ini dapat terbentuk pada jangka waktu yang sangat panjang dan juga tentunya penuh dengan pengorbanan dalam menjalani kehidupannya, maka diperlukan penerapan nilai-nilai luhur khususnya nilai yang terkandung dalam Pancasila guna menjadi cerminan kepribadian bangsa. Dan sangat perlu untuk kita sebagai masyarakat Indonesia ketahui bahwasanya di dalam Menurut (Margono, 2012) Pancasila banyak nilai-nilai luhur dan baik yang harus kita jadikan pandangan maupun pedoman dalam hidup bermasyarakat agar hidup kita dapat berlandaskan nilai Pancasila sehingga menjadikan kita warga negara yang baik dan tentunya memiliki sikap nasionalisme, patriotisme, cinta tanah air dan tertanam sifat yang Pancasilaisme. Jikalau begitu Pancasila akan dapat dijadikan pedoman hidup bangsa yang baik karena memiliki banyak nilai yang sangat bermakna bagi kehidupan bangsa Indonesia. Maka tujuan penelitian ini ialah untuk mengetahui beberapa pengaruh globalisasi dan Revolusi Industri 4.0 yang mungkin berdampak buruk terhadap nasionalisme suatu negara di era modern ini dimana sebagian besar rasa nasionalisme negara tersebut berkurang bahkan tersesat.

\section{METODE PENELITIAN}

Metode yang digunakan pada penelitian menggunakan metode kualitatif yang bersifat deskriptif dengan menggunakan metode studi literatur. Menurut pendapat (Mulyo, 2012) metode tersebut merupakan metode dengan membandingkan beberapa pendapat suatu tokoh dan langkah selanjutnya penulis haruslah mebuat suatu kesimpulan. Peneliti melakukan analisis dari berbagai sumber literatur dalam mencari sumber teori dan dasar pembahasannya yang nantinya dapat dijadikan sebuah kesimpulan. Peneliti melakukan studi kepustakaan untuk memperoleh sumber penelitiannya dari berbagai macam sumber seperti jurnal akreditas sinta atau jurnal yang bereputasi juga buku yang penulis analisis dan kaji lebih dalam dengan memanfaatkan data atau teori yang sudah penulis analisis dengan bentuk deskriptif. Hasil pengolahan data tersebut akan 
5229 Revitalisasi Pancasila dalam Memfilter Dampak Globalisasi dan Era Revolusi Industri 4.0 Alexandria Sarah Vania, Dinie Anggraeni Dewi, Fajriatur Robi'ah, IkhsanFitrianCatur Nugraha, Yayang Furi Furnamasari

DOI: https://doi.org/10.31004/basicedu.v5i6.1612

dianalisis dengan tersusun dan terperinci sehingga menciptakan sebuah kesimpulan. Peneliti perlu mencari sumber teori yang berkesinambungan dengan penelitian revitalisasi Pancasila sebagai penyaring dampak negative dari globalisasi dan revolusi yang terjadi saa tini.

\section{HASIL DAN PEMBAHASAN}

\section{Peran Pancasila DalamPemfilteran Budaya Asing}

Hasil dari penelitian yang telah penulis simpulkan dari beberapa kajian sumber ialah Pancasila ini merupakan pandangan hidup dari bangsa kita yakni bangsa Indonesia maka sangatlah berperan penting dalam hal pemfilteran budaya asing di era revolusi modern ini atau revolusi Industri 4.0. Pancasila harus dan wajib menjadi trandsetter dalam hal ini. Pancasila harus menjadi pijakan dalam bersikap, dan menjalani kehidupan bermasyarakat karena Pancasila merupakan dasar negara dan ideologi bangsa Indonesia sehingga tentunya memiliki tingkatan yang sejati dan juga abadi di dalam jiwa masyarakat dan negara kita yakni bangsa Indonesia pernyataan berikut menurut pendapat (Untari., 2012). Rakyat yang berkembang dan tumbuh di atas pengaruh buruk atau baiknya kepribadian dan budaya negara asing mungkin saja akan mendatangkan kemajuan atau hal positif, tetapi tidak menutup kemungkinan jikalau bisa saja kemajuan itu akan menjadikan rakyat Indonesia menjadi asing dan tidak suka akan jati dirinya atau identitasnya sendiri.

Lebih lanjut menurut pandangan (Subekti, 2018) intinya di era ini yang serba berorientasi teknologi menjadi suatu tantangan besar pada generasi terbaru. Untuk mengatasi problematika tersebut ada bebagai cara atau sistematika yang bisa diterapkan, salah satunya adalah dengan meningkatkan kemampuan, keterampilan dan kemahiran dalam menghadapi teknologi, baik secara penggunaanya dan pemanfaatannya.

Menurut (Yetti, 2014) urgensi Pancasila dalam era modern ini atau globalisasi di era revolusi industri 4.0 ini terdapat banyak hal yang dapat kita rasakan dimana tentu saja tidak adanya batasan atau sanggahan yang jelas dan tegas antar negara Indonesia dan negara asing. Karena itu peran dari Pancasila inilah yang sangat penting dalam menghadapi hal ini yakni pengaruh negatif dari era modern ini atau era globalisasi dan revolusi industry 4.0 dalam segala aspek yaitu dengan cara menyaring pengaruh budaya asing melalui penerapan Pendidikan Pancasila dan Kewarganegaraan yang diterapkan dalam kehidupan berbangsa dan bermasyarakat juga bernegara. Dengan adanya pendidikan tersebut tentu saja dapat dijadikan tumpuan dan pola yang mendasar dan juga sebagai arahan yang positif sebagai usaha kita dalam menghadapi krisis dan juga disintegrasi bangsa yang di era modern dan globalisasi sekarang ini. Hal tersebut dilaksanakan untuk upaya Indonesia dalam menjaga nilai baik yang terkandung dalam nilai-nilai Pancasila yang berkedudukan sebagai dasar negara Indonesia dan juga sebagai ideologi nasional.

Oleh karena penjelasan diatas maka sangat perlu adanya persiapan yang sangat matang dalam memperhatikan lahirnya generasi muda yang tentunya sangat sadar Pancasila dan harus terdidik dengan baik. Karena banyaknya nilai moral baikyang terkandung di dalam Pancasila dilansir oleh (Heri Kurnia, 2021). Sehingga diharapkan untuk kehidupan di masa mendatang haruslah tercipta generasi muda penerus bangsa yang mampu menciptakan kesejahteraan sosial dalam kehidupan bangsa Indonesia, serta menciptakan pertumbuhan ekonomi dan juga moral yang baik. Selain penjelasan itu juga adapaun berbagai cara mangatasi dampak dari adanya era modern ini atau globalisasi yakni adanya Pancasila yang wajib digenggam teguh dan kokoh oleh masyarakat kita karena tentunya berperan sebagai pandangan hidup dalam bermasyarakat dan bersosial yang wajib dijadikan acuan dalam bersikap. Kita selaku warga negara Indonesia yang baik seharusnya bisa mengimplementasikan nilai-nilai baik yang terkandung dalam Pancasila. Contohnya yakni nilai human instrument yang adil dan beradab. Pada pernyataan itu Pancasila menuntut bahwasannya kita sebagai warga negara yang baik harus memiliki kesadaran akan sikap dan perilaku kita yang perlu disesuaikan dengan nilai - nilai moral dalam hidup bersama. Dapat disimpulkan bahwa Pancasila memiliki peran aktif 
5230 Revitalisasi Pancasila dalam Memfilter Dampak Globalisasi dan Era Revolusi Industri 4.0 Alexandria Sarah Vania, Dinie Anggraeni Dewi, Fajriatur Robi'ah, IkhsanFitrianCatur Nugraha, Yayang Furi Furnamasari

DOI: https://doi.org/10.31004/basicedu.v5i6.1612

dalam menyaring banyaknya budaya asing yang masuk kedalam negara Indonesia. Menurut (Lisa Retnasari, 2020) dibalik semua halitu masyarakat khususnya mahasisa dan warga negara muda , diperlukan adanya kesadaran diri dan introfeksi diri dari kita sebagai bangsa yang memiliki jiwa Pancasila dalam jati diri bangsa. Kita harus bisa memilih budaya yang sejalan dengan jati diri kita untuk terapkan di kehidupan sehari-hari, bukannya memaksa kebudayaan luar yang berlawanan dengan jati diri dan nilai moral bangsa tersebut untuk terapkan di kehidupan sehari hari.(Angga, 2018).

\section{Tingkah Laku Masyarakat Di Era Revolusi Industri 4.0}

Berdasarkan penelitian penulis dalam buku yang ditulis dan dirilis oleh (Ali, 2011) secara detail menjelaskan keunikan dari generasi milenial dibandingkan dengan generasi - generasi sebelumnya. Salah satu perbandingannya yaitu terlihat bahwa karakteristik generasi milenial yang tidak bisa dilepaskan dan bergantung pada teknologi, terutama internet dan juga hiburan yang sudah menjadi kebutuhan pokok bagi mereka. Dengan adanya kemajuan di era globalisasi ini diharapkan tidak melunturkan nilai Pancasila generasi milenial dalam berpikir dan bertindak. Karena sudah kewajiban untuk kita menjaga jati diri bangsa agar tetap merdeka.

Perbedaan generasi tentunya selalu ada dalam perkembangan kehidupan dan manajemen sumber daya manusia. Konsep perbedaan setiap generasi pun terus berkembang dari waktu ke waktu. Karakteristik generasi milenial dapat dideskripsikan sebagai generasi yang berbasis teknologi, terdidik dan berpengetahuan, sadar secara sosial, merangkul pengalaman dan pengeluaran etis, serta sadar secara kesehatan, keuangan, dan spiritual (J Sumardianta, 2018). Berikut ini ialah beberapa perilaku masyarakat milenial saat ini berdasarkan pengamatan, antara lain adalah:

1) Kecanduan internet yang dapat dibuktikan dengan penggunaan sertat ingkat kebutuhan internet di Indonesia yang semakin dan terus meningkat setiap harinya. Generasi zaman now bukan hanya menggunakan internet untuk mencari materi pelajaran tetapi juga internet digunakan untuk bermain game online yang membuat mereka kecanduan internet dan melupakan tugasnya yang lain. Sikap ini sangat tidak baik untuk masa perkembangan anak terutama anak usia dini karena akan membuat anak tersebut bergantung pada internet.

2) Tidak teguh pendirian. Contohnya adalah dalam hal memilih produk yang disukai akan lebih mudah berganti produk hanya karena pengaruh dari orang lain yang belum tentu kebenarannya. Hal lain juga dapat dilihat dari pemilihan minat anak yang cenderung mengikuti kemauan orang tua atau pengaruh sekitarnya. Yang membuat anak gagal untuk menemukan bakat dalam dirinya.

3) Tidak mau ribet. Generasi milenial cenderung menyukai hal praktis yang tidak menyulitkan dirinya. Contohnya adalah saat melakukan transaksi pembayaran, generasi milenial cenderung memilih melakukan pembayaran non tunai. Hal ini dikarenakan kebiasaan atau pengaruh lingkungan yang juga melakukan hal yang sama.

4) Kerja cepat dan cerdas. Pada perkembangan teknologi saat ini, generasi milenial memiliki kelebihan mengenai teknologi karena sudah menjadi bagian dari hidupnya. Dimana generasi milenial cepat beradaptasi, tidak pantang menyerah dan juga diperkirakan generasi milenial lebih efektif dibandingkan dengan generasi sebelumnya.

5) Bisa melakukan banyak hal. Kemajuan zaman memaksa kita untuk beradaptasi dengah perubahan. Seperti halnya dengan generasi milenial yang selalu membuka diri untuk menerima hal baru dari pihak lain. Generasi millenial memiliki kepekaan yang tinggi dan rasa ingin terlibat dalam suatu hal yang menunjukkan kekuasaan mereka.

6) Cuek dengan politik. Hal ini dikarenakan generasi milenial sudah disibukkan dengan dunia internet sehingga melupakan masalah dalam dunia politik. Generasi milenial lebih senang membicarakan perihal 
5231 Revitalisasi Pancasila dalam Memfilter Dampak Globalisasi dan Era Revolusi Industri 4.0 Alexandria Sarah Vania, Dinie Anggraeni Dewi, Fajriatur Robi’ah, IkhsanFitrianCatur Nugraha, Yayang Furi Furnamasari

DOI: https://doi.org/10.31004/basicedu.v5i6.1612

musik, olahraga, game online dan trend terkini dibandingkan dengan membahas masalah politik di Indonesia. Berdasarkan hal diatas sikap generasi milenial memiliki kelebihan dan kekurangan dari adanya dampak kemajuan teknologi ini. hal ini harus menjadi perhatian untuk kita dalam mencegah dampak negatif agar karakter generasi milenial dapat lebih baik lagi dalam menerima budaya baru yang masuk ke Indonesia. Karena setiap generasi milenial mempunyai karakteristik yang tentunyaberbeda. Hal tersebut disebabkan oleh faktor seperti latar belakang tempat tinggal yang berbeda, strata ekonomi yang berbeda, kondisisosial keluarga yang berbeda, dan pola komunikasi yang berbedayaitulebih terbuka dibandingkan generasi sebelumnya.

Masyarakat tentunya menginginkan generasi mudanya yang bisa berpartisipasi dalam menjalankan kehidupan berbangsa dan bernegara, dengan budi pekerti luhur. Untuk mewujudkannya, media yang dapat digunakan adalah melalui penerapan Pendidikan Kewarganegaraan dalam kehidupan sehari-hari, khususnya dalam bersosialisasi di era globalisasi dan revolusi industri 4.0 ini (Amalia Dwi Pertiwi, 2021).

\section{Pancasila Sebagai Dasar Nilai Dalam Strategi Pengembangan Ilmu Pengetahuan Dan Teknologi}

Menanamkan dan mempertahankan karakter pancasila dalam diri generasi muda merupakan langkah utama untuk membentuk dan membangun pola pikir dan perilaku seseorang agar menjadi pribadi yang positif sehingga dapat bermanfaat bagi bangsa dan negara (Meitriana Mezi, 2020). Peran Pancasila ini dalam memfilter teknologi yang dominannya dipengaruhi oleh bangsa asing harus adanya strategi yang sangat tepat untuk paradigma tersebut. Perannya Pancasila dalam pengembangan ilmu dan teknologi harus sampai pada masyarakat agar menumbuhkan kesadaran mengenai fanatisme kaidah kenetralan keilmuan yang hanya akan menjebak diri dalam banyak masalah sehingga permasalahan tidak dapat diatasi dengan mudah dengan hanya berpegang teguh pada kaidah ilmu yang dikajinya, khusunya yang mencakup tentang pertimbangan religious ,etis, apatis dan beberapa nilai budaya yang memiliki sifat mutlak bagi kehidupan manusia yang memiliki budaya.

\section{Peran Pancasila di Era Globalisasi dalam menumbuhkan Kesadaran Nasionalisme}

Globalisasi membawa tiga kecenderungan yakni homogenisasi, hibridisasi dan perbedaan dalam aspek kehidupan. Homogenitas terjadi dengan ditandai masayarakat Indonesia secara luas menggunakan merekmerek barat meskipun tidak asli. Hibridsasi berlangsung dengan adanya produk global yang diadaptasi dan dimodifikasi oleh dan untuk kondisi lokal dengan pencampuran kultur. (Lisa Retnasari, Menemukan Sikap Nasionalisme Warga Negara Muda di Era Globalisasi Melalui Pendidikan Kewarganegaraan di Perguruan Tinggi, 2020)Dilansir menurut (Rasid, 2013) mengemukakan bahwa generasi muda dapat dan mampu mengembangkan karakter nasionalisme dengan melalui tiga tahapan yaitu :

1. Karakter serta moral yang dimilikiolehgenerasi muda perlu dijadikan model dalam pengembangan karakter bangsa yang sudahpasti harus positif, dengan selalu inisiatif dan tidak bersifat apatis dalam membangun kesadaran yang tinggi. misalnya menyerukan penyelesaian masalah atau solusi dari permasalahan.

2. Pembangun karakter yang artinya generasi muda sangatlah berperan untuk membangun karakter yang tentunya positif.

3. Perekayasa karakter artinya adalah generasi muda memiliki peran penting dalam mengembangkan prestasi di bidang ilmu pengetahuan dan kebudayaan, serta terlibat ke dalam proses pembelajaran pengembangan karakter positif bangsa yang sesuai dan sejalan dengan perkembangan zaman.

Pendidikan karakter berusaha mengembangan para siswa untuk memiliki sikap yang bertanggung jawab, kretivitas dan berpikir kritis (Mitra Kasih La Ode Onde, 2020). Dari adanya konsep tersebut maka dapat disimpulkan bahwa generasi muda merupakan pilar bangsa. Kita sselaku warga negara Indonesia tentunya memiliki peran yang sangatlah penting dalam terbentuk dan terbangunnya bangsa. Masa depan 
5232 Revitalisasi Pancasila dalam Memfilter Dampak Globalisasi dan Era Revolusi Industri 4.0 Alexandria Sarah Vania, Dinie Anggraeni Dewi, Fajriatur Robi’ah, IkhsanFitrianCatur Nugraha, Yayang Furi Furnamasari

DOI: https://doi.org/10.31004/basicedu.v5i6.1612

bangsa sangatlah bergantung pada generasi muda khususnya dalam bersikap dan juga bertindak. Maka dari itu, generasi muda perlu menjunjung nilai-nilai moral yang baik berdasarkan nilai-nilai Pancasila dan mengimplementasikannya dalam kehidupan bermasyarakat, berbangsa dan bernegara. Selain itu, perlu ditanamkan rasa nasionalisme yang tinggi dengan menanamkannya sejak dini pada kalangan generasi muda. Nasionalisme ini berarti menjunjung tinggi nama bangsa dan negara Indonesia dengan tetap memiliki rasa menghormati dan menghargai bangsa lain. Dalam hal ini, Pancasila tentunya sangat berperan guna menumbuhkan rasa patriotisme dan nasionalisme dalam diri generasi muda. Sikap serta perilaku dalam bertindak yang dilakukan oleh generasi muda harus selalu didasarkan oleh nilai-nilai Pancasila dan mencerminkan jati diri bangsa yang baik.

Menurut (Alim, 2011) rasa nasionalisme dan cinta pada tanah air perlu disampaikan secara baik dan benar, yaitu sesuai dengan norma dan kaidah yang berlaku dalam bermasyarakat terutama norma yang terkandung dalam Pancasila. Menurut (Purwandi, 2017) sikap nasionalisme yang kita tanamkan haruslah sejalan dengan Pancasila yang merupakan dasar negara dan pandangan hidup bangsa serta ideologi negara, sehingga wujud nasionalisme yang tertanam dalam diri kita bukan nasionalisme dalam arti sempit akan tetapi sebagai nasionalisme yang berarti luas. Kita harus memiliki rasa cinta kepada bangsa dan Negara kita namun nilai sopan dalam menghargai dan menghormati bangsa lain tetap perlu dipertahankan. Kita tidak perlu menentang ataupun menolak budaya asing yang masuk ke negara kita, akan tetapi kita juga tidak boleh asal menerima budaya asing tersebut. Budaya asing tersebut harus kita saring terlebih dahulu dengan dengan mengimplementasikan nilai-nilai Pancasila.

\section{Implementasi Nilai Pancasila Di Era Globalisasi}

Pada penelitian yang dilakukan oleh (Damanhuri, 2016) mengemukaan bahwa Pancasila merupakan hal yang sangat penting sebagai acuan maupun pedoman mengenai bagaimana warga negara dapat berperilaku dengan baik di dalam berkehidupan sosial, atau biasa kita sebut dengan good citizen. Dengan penerapan nilainilai Pancasila tersebut diharapkan dapat memberikan pengajaran terhadap masyarakat mengenai cara berpikir dan bertindak agar sesuai dengan ideologi negara dan tidak berlawanan dengan nilai moral yang ada. Berikut ialah contoh pengimplementasian Pancasila dalam bermasyarakat. Menekuni Pendidikan dengan baik terutama di bidang kewarganegaraan, memfilter budaya asing yang masuk ke Negara Indonesia, memperdalam religius di kehidupan, mempererat persatuan dalam menghadapi berbagai perbedaan, memanfaatkan teknologi dengan efektif dan cerdas, manfaatkan budaya asing sebagai pedoman kita untuk memotivasi dalam menciptakan inspirasi dan aspirasi, jadikan perbedaan sebagai alat dalam melengkapi satu sama lain

\section{KESIMPULAN}

(Efendi, 2020) berpendapat bahwa dalam menjalani kehidupannya, diperlukan penerapan nilai-nilai luhur khususnya nilai yang terkandung dalam Pancasila guna menjadi cerminan kepribadian bangsa khususnya pada era modern ini. Pancasila sangat berperan sebagai solusi dalam upaya memfiltrasi dampakdampak negatif yang timbul sebab adanya globalisasi di era revolusi Industri 4.0. Maka dari itu karakter Pancasila harus diterapkan oleh masyarakat Indonesia dengan melakukan penerapan nilai-nilai moral yang terkandung didalamnya. Menurut dengan adanya suatu pendidikan berpancasila dalam kewarganegaraan bisa kita jadikan suatu dasar juga transeter juga arahan untuk upaya menanggulangi juga mengatasi krisis bangsa dan disintegrasi Indonesia yang sedang dihadapi, khususnya pada era globalisasi sekarang ini. 
5233 Revitalisasi Pancasila dalam Memfilter Dampak Globalisasi dan Era Revolusi Industri 4.0 Alexandria Sarah Vania, Dinie Anggraeni Dewi, Fajriatur Robi’ah, IkhsanFitrianCatur Nugraha, Yayang Furi Furnamasari

DOI: https://doi.org/10.31004/basicedu.v5i6.1612

\section{DAFTAR PUSTAKA}

Ali, H. (2011). Milenial Nusantara. Jakarta: Gramedia Pustaka Utama.

Alim, M. A. (2011). Implementasi Nilai-Nilai Pancasila Untuk Menumbuhkan Nasionalisme Bangsa. Stmik Amikom.

Amalia Dwi Pertiwi, S. A. (2021). Implementasi Nilai Pendidikan Karakter Dalam Mata Pelajaran Pkn Di Sekolah Dasar. Jurnal Basic Edu, 4328-4333.

Angga, M. P. (2018). Pembelajaran Ppkn Dalam Resonansi Kebangsaan Dan Globalisasi. Jurnal Ilmih Ilmu Sosial, 120-126.

Bakri. (2016). Studi Awal Implementasi Internet Of Things Pada Bidang Pendidikan. Jrec: Jurnal Of Electrical And Electronic, 18-23.

Damanhuri. (2016). "Implementasi Nilai-Nilai Pancasila Sebagai Upayapembangunan Karakter Bangsa.". Untitra Civic Education.

Efendi, Y. H. (2020). "Penerapan Nilai-Nilai Pancasila Dalam Lembaga. Jpk.

Heri Kurnia, A. N. (2021). Model Perencanaan Pembelajaran Ppkn Berbasis Literasi. Jurnal Basic Edu, $733-$ 740.

Herlambang, Y. T. (2015). Pendidikan Kearifan Etnik Dalam Mengembangkan Karakter. . Jurnal Pendidikan Dasar Kampus Cibiru , 1-11.

J Sumardianta, W. K. (2018). Mendidik Generasi Z. Gramedia Widia Sarana Indonesia.

Kaelan, Z. A. (2010). Pendidikan Kewarganegaran Untuk Perguruan Tinggi. Yogyakarta: Paradigma.

Lisa Retnasari, Y. H. (2020). Menemukan Sikap Nasionalisme Warga Negara Muda Di Era Globalisasi Melalui Pendidikan Kewarganegaraan Di Perguruan Tinggi. Jurnal Basic Edu, 79-88.

Lisa Retnasari, Y. H. (2020). Menumbuhkan Sikap Nasionalisme Warga Negara Muda Di Era Globalisasi Melalui Pendidikan Kewarganegaraan Di Perguruan Tinggi. Jurnal Basic Edu, 79-88.

Margono. (2012). Landasan Dan Tujuan Pendidikan Pancasila. Malang.

Meitriana Mezi, J. A. (2020). Implementation Of Character Education In The Student Council. Jurnal Basic $E d u, 765-774$.

Mitra Kasihla Ode Onde, H. A. (2016). Integrasi Penguatan Pendidikan Karakter Era 4.0 Pada Pembelajaran Berbasis Tematik Dan Integratif. Jurnal Basic Edu, 268-279.

Mulyo. (2012). Model Pembelajaran Inovatif. Yogyakarta: Gava Media.

Purwandi, A. H. (2017). Milenial Nusantara. Jakarta: Gramedia Pustaka Utama.

Rasid, Y. (2013). Transformasil Nilai-Nilai Budaya Lokal Sebagai Upaya Pembangunan Karakter Bangsa . Jurnal Penelitian Pendidikan, 67-79.

Subekti. (2018). Mengembangkan Literasi Informasi Melalui Belajar Berbasis Kehidupan Terintegrasi Untuk Menyiapkan Calon Guru Sains Dalam Menghadapi Era Revolusi Industri 4.0. Review Literature, Education And Human Development Journal, Vol 3 No 1.

Untari., S. (2012). Pancasila Dalam Kehidupan Berasyarakat, Berbangsa, Dan Bernegara” Dalam Margono. Pendidikan Pancasila Topik Aktual Kenegaraan.

Yetti, H. (2014). Urgensi Eksistensi Pancasila Di Era Globasilasi (Studi Kritis Terhadap Persepsi Mahasiswa Stkip Pgri Sumenep Tentang Eksistensipancasila). Volume 6 No 2. 